American Journal of Applied Sciences 9 (6): 934-937, 2012

ISSN 1546-9239

(C) 2012 Science Publications

\title{
Schedule Planning for Repairing Power Supply System
}

\author{
Kuo-Wei Lin and Chein-Jen Kang \\ Department of International Business, \\ Hsuan Chuang University Hsinchu Taiwan, 30092, R.O.C., Taiwan
}

\begin{abstract}
Problem statement: Taiwan is located in the tropical ocean areas. The strong typhoon in summer often causes the collapse of electric transmission towers and results in power outages that seriously affect people's lives and industrial production. Approach: In light of this situation, this study aims to employ project management techniques of Theory of Constraints (TOC) to develop a practical TOC model to quickly repair the towers and restore power supplied system. Results: The actual application had verified that the research model could not only shorten the duration of work but also save the manpower and material expenses. Conclusion: It once again proved the excellent results of reparation operations by applying TOC to project management.
\end{abstract}

Key words: Theory of Constraints (TOC), buffer management, project management, critical path method, Program Evaluation and Review Technique (PERT), electric transmission

\section{INTRODUCTION}

A typhoon ravaged southern Taiwan causes the collapse of galvanized electric towers \#33, \#47 in the mountain-sea lines from Dapeng to Fenggang and paralyzes the power supply system. The power outage not only affected people's life but also stopped the operation of industrial and commercial activities. The study thus aims to plan a project management scheduling for quickly repairing power supply system.

This study employs the thinking logic of TOC to plan a complete operation scheduling. At first, we find out the potential bottlenecks for entire project construction and give careful discussions. Through brain storms, the major bottlenecks in the project were found. Then some best solutions are selected to make breakthroughs of the bottlenecks. After the breakthrough, the rest of nonbottleneck operations are quickly implemented that the all project management operations could finally smoothly completed in the optimal situation.

\section{MATERIALS AND METHODS}

In a rapidly changing competitive environment, the integration of resources and the focus of the strategy are extremely important. However, facing the impact of changes of external environment and the uncertain factors of internal organization, human resources and process, a firm may not able to effectively achieve the goal of maximizing profit. Therefore, in recent years, many firms have sought for improvement by employing the thinking and management model of TOC with a hope that it could make a breakthrough to the bottlenecks to effectively enhance operational efficiency and achieve the corporate goal.

The thinking process of TOC: Goldratt (1999) employed the thinking process of TOC to allow the individual and organization use strict cause-effect to ensure that the improvement could result in significant results. But firstly, they need to know what to change and the core of the problem plus what to change to and how to cause the change. Rigorously answering the three questions through process management procedures is the factor for on-going improvement and the framework advocated by the thinking process of TOC. Goldratt (1999) also defined the three steps of change as a Process of on-going Improvement (POOGI).

The management thinking of TOC: Lee and Zhang (2005) argued that TOC is a solution of the combination of logic and common sense for operation and management. Based on the thinking process of scientific method $(\mathrm{P} \rightarrow \mathrm{D} \rightarrow \mathrm{C} \rightarrow \mathrm{A})$, three basic hypotheses for the organization were (1) an organization had at least one goal to achieve; (2) an organization was a system that was composed of many departments or units and were interdependent; and (3) any organization should have their own constraints that prevented the organization from better performance for targets, that was constraints or bottlenecks. 
When an organization cannot accelerate to achieve the goal, they should deeply explore the reason. They should find that such constraints are related with organization's own policy, performance evaluation, management thinking and organizational structure. The constraints prevent the entire operational chain from better output. The TOC have been developed following five focusing steps: (1) identify the system's constraint; (2) decide how to exploit the system's constraint; (3) subordinate everything else to the above decision; (4) Elevate the system's constraint and (5) if in the previous steps a constraint has been broken, go back to step 1 .

Project management solution of TOC: Uncertainty is a common characteristic of project management that in planning project, you must first take into account the uncertain factors and expand slightly the completion time and budget to ensure that the promised completion time, contents and budget meet the requirement of the planning. Then find out critical path that is the longest path in the project network in which if any single operation in the path cannot complete on schedule, the entire project will be delayed. So the total time of the entire project is the total amount of complete time of each single operation. Therefore, in implementing the project management, you only have to control the complete time of each single operation to complete the entire project on schedule. However, the actual situation is not the case. According to Guiterrez and Kouvelis (1991) the statement of Parkinson's Law, if the project staff feel there is plenty of time to complete it, they will slow down the pace of work or add some other works that will waste time allocated for the project and delay instead the deadlines for completing the project management. Also based on the "student syndrome" mentioned by Goldratt (1999) that the project staffs usually rush to work until the completion datelines approaching just like students who usually study hard until an examination approaching. So if we give the staff plenty time for completion in planning a project, the staff may lose their positive attitude toward the project and finally not only use up all of the allowable time but also delay the completion time for the entire project. Therefore, Schragenheim and Ronen (1991) introduced buffer management that when the implementation of project deviated from the promised, it should be immediately corrected.

Besides, Goldratt (1997) also introduced the management strategy for critical chain scheduling. That is, during the scheduling, in addition to taking account of the interdependency of resources for the operation, the management should also appropriately integrate the operations. When we determine a path as the critical chain scheduling, we should take the interdependency of resources into consideration.

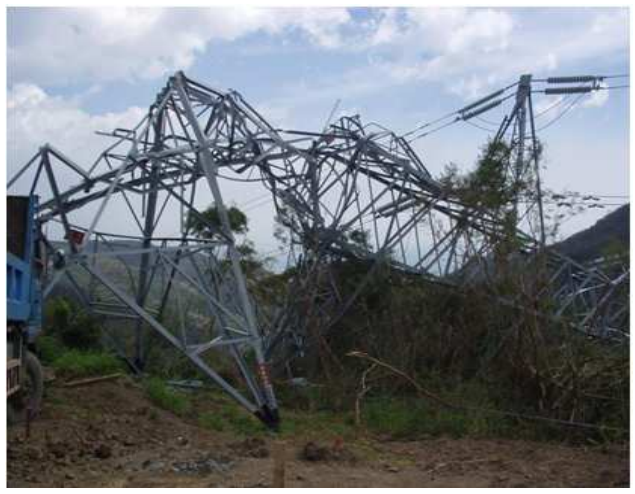

(a)

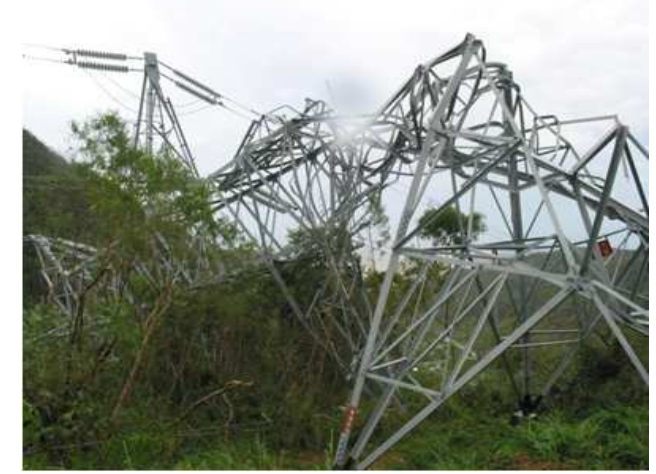

(b)

Fig. 1: Front view (a) Side view (b) collapse of tower \#47 of sea and mountain-line from Japan to fenggang

Meanwhile, we should also use a buffer and integration management to protect the critical chain from the impact of non-critical chains in the implementation. This is the most robust project management approach at the present time that could not only shorten the project completion time but also reduce the cost and enhance the quality of product. Therefore, this study uses TOC mechanism to plan following repair work of power supply system.

Practical example: A typhoon stormed the southern tip of Taiwan, causing the collapse of Taiwan power company's \#47 galvanized tower for electric transmission on mountain-sea line from Japan to fenggang at the site of $161 \mathrm{KV}$ as Fig. 1.

\section{RESULTS AND DISCUSSION}

It is important to repair the power supply system as soon as possible to satisfy the demand of people's livelihood and industry after the disasters. This study employed TOC to introduce five focusing steps in the resource investigation. 


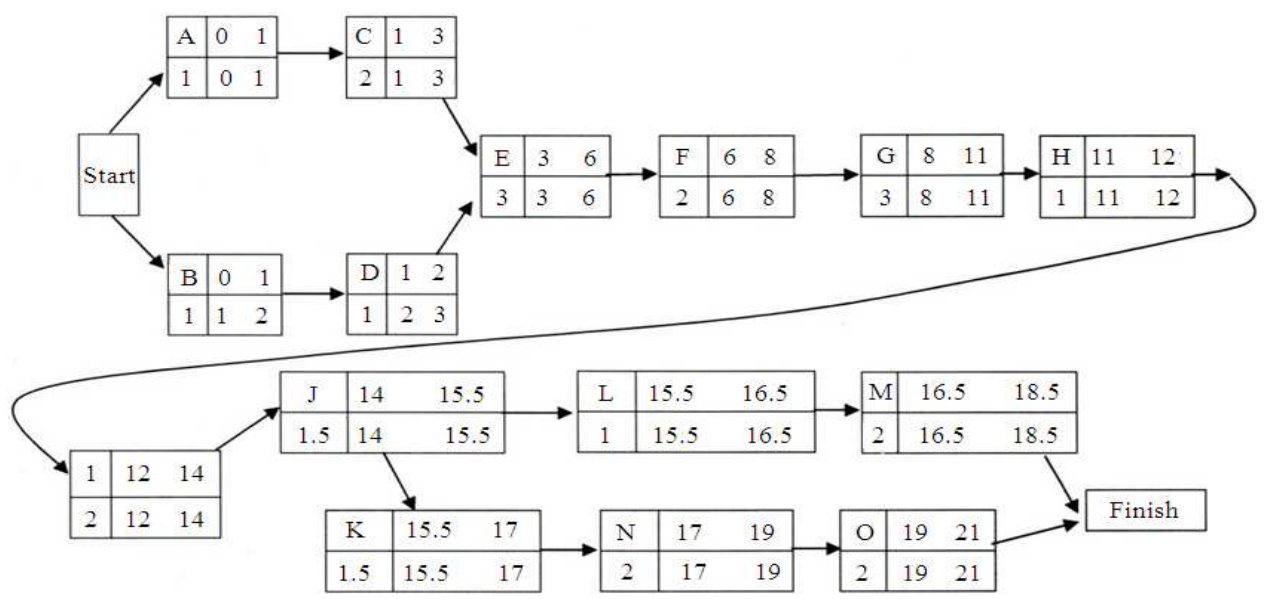

Fig. 2: project network diagram for repairing power supply system

Table 1: Work breakdown structure

\begin{tabular}{|c|c|c|c|}
\hline Activity & Days needed & Preceding activity & Succeeding activity \\
\hline $\begin{array}{l}\text { Site preparation by excavator, tower foundation } \\
\text { stakeout. Measurement }\end{array}$ & 1.0 & - & $\mathrm{C}$ \\
\hline Big moving of tower & 1.0 & - & $\mathrm{D}$ \\
\hline Excavation of tower foundation PC laying & 2.0 & A & E \\
\hline Small moving of tower & 1.0 & B & E \\
\hline Assembly, erection and set up of tower & 3.0 & $\mathrm{D}$ & $\mathrm{F}$ \\
\hline Backfill tower foundation, assembly and build tower foot & 2.0 & E & $\mathrm{G}$ \\
\hline Assembly and build tower body, bolt trimming & 3.0 & $\mathrm{~F}$ & $\mathrm{H}$ \\
\hline Dismantle old tower, remove sea-line wire to new tower & 1.0 & G & I \\
\hline $\begin{array}{l}\text { Adjustment of side relax of \#47 \#48 of sea-line, end crimp, } \\
\# 47 \sim \# 46 \text { wire connection in the air and removes to new tower. }\end{array}$ & 2.0 & $\mathrm{H}$ & $\mathrm{J}$ \\
\hline Adjustment of side relax of \#47 \#46 of sea-line, end crimp & 1.5 & I & $\mathrm{L}$ \\
\hline Adjustment of side relax of \#47 \#48 of mountain-line end crimp & 1.5 & G & $\mathrm{N}$ \\
\hline Install spacer and jumper for \#47 \#46 \#48 of sea-line & 1.0 & $\mathrm{~J}$ & M \\
\hline Replace OPGW of \#46 \#47 \#48 OPGW of se-line, transmission & 2.0 & $\mathrm{~L}$ & - \\
\hline $\begin{array}{l}\text { Wire connection in the air for } \# 47 \sim \# 46 \text { of mountain-line and remove to } \\
\text { new tower, adjustment of side relax and end crimp }\end{array}$ & 2.0 & K & $\mathrm{O}$ \\
\hline 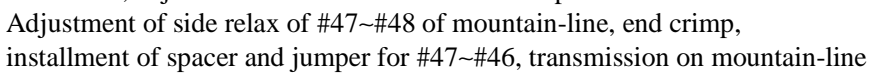 & 2.0 & $\mathrm{~N}$ & $\mathrm{P}$ \\
\hline
\end{tabular}

Table 2: Data needed for activity slack calculation

\begin{tabular}{|c|c|c|c|c|c|c|}
\hline \multirow{2}{*}{$\begin{array}{l}\text { Earliest } \\
\text { activity }\end{array}$} & \multirow{2}{*}{$\begin{array}{l}\text { Latest } \\
\text { Start (ES) }\end{array}$} & \multirow{2}{*}{$\begin{array}{l}\text { Earliest } \\
\text { Start (LS) }\end{array}$} & \multicolumn{2}{|c|}{ Latest critical } & \multirow{2}{*}{$\begin{array}{l}\text { slack } \\
\text { (LS-ES) }\end{array}$} & \multirow{2}{*}{$\begin{array}{l}\text { critical } \\
\text { path }\end{array}$} \\
\hline & & & Finish (EF) & Finish (LF) & & \\
\hline A & 0.0 & 0.0 & 01.0 & 1.0 & 0.0 & $\sqrt{ }$ \\
\hline B & 0.0 & 1.0 & 1.0 & 2.0 & 1.0 & \\
\hline $\mathrm{C}$ & 1.0 & 1.0 & 3.0 & 3.0 & 0.0 & $\sqrt{ }$ \\
\hline D & 1.0 & 2.0 & 2.0 & 3.0 & 1.0 & \\
\hline E & 3.0 & 3.0 & 6.0 & 6.0 & 0.0 & $\sqrt{ }$ \\
\hline $\mathrm{F}$ & 6.0 & 6.0 & 8.0 & 8.0 & 0.0 & $\sqrt{ }$ \\
\hline G & 8.0 & 8.0 & 11.0 & 11.0 & 0.0 & $\sqrt{ }$ \\
\hline $\mathrm{H}$ & 11.0 & 11.5 & 12.0 & 12.0 & 0.0 & $\sqrt{ }$ \\
\hline I & 12.0 & 12.0 & 14.0 & 14.0 & 0.0 & $\sqrt{ }$ \\
\hline $\mathrm{J}$ & 14.0 & 14.0 & 15.5 & 15.5 & 0.0 & $\sqrt{ }$ \\
\hline K & 15.5 & 15.5 & 17.0 & 17.0 & 0.0 & $\sqrt{ }$ \\
\hline $\mathrm{L}$ & 15.5 & 15.5 & 16.5 & 16.5 & 0.0 & $\sqrt{ }$ \\
\hline M & 16.5 & 16.5 & 18.5 & 18.5 & 0.0 & $\sqrt{ }$ \\
\hline $\mathrm{N}$ & 17.0 & 17.0 & 19.0 & 19.0 & 0.0 & $\sqrt{ }$ \\
\hline $\mathrm{O}$ & 19.0 & 19.0 & 21.0 & 21.0 & 0.0 & $\sqrt{ }$ \\
\hline
\end{tabular}

It found that the tower materials, iron fittings, wire, construction equipment and manpower were limited. So we sufficiently integrated the all resources and made breakthroughs. With reference of Kerzner (2009) projection management, the relationship between the preceding operation and the succeeding operation in Table 1 and the network diagram of construction project were established as Fig. 2. Then we figured out 18.5 days for restoring electricity transmission on sealine and 21.0 days on mountain-line.

Finally we find out critical path according to construction scheduling for the project in Table 2.

After identifying critical path, immediately begin the detail work of construction 1 through 4. Firstly repair the sea-line that the power supply could be restored as soon as possible to solve the demand of power from people's livelihood: 
Am. J. Applied Sci., 9 (6): 934-937, 2012

Step 1: Inspect power outage

Step 2: Dismantle damanged tower and assembly new tower

Step 3: Move the sea-line cable

Step 4: Prepare power transmission on sea-line

When the sea-line transmits the electricity on schedule, the operations of step 5 to step 8 are still under way. The reparation work should give special attention to the safety distance to avoid any electric shock accident and ensure the smooth operation. Due to the proper precautionary measures in advance, the mountain-line restored power supply within the time frame too that in 21 days the power supply had restored to normal from the poor quality caused by the typhoon:

Step 5: Power transmission on sea-line Step 6: Move the cable of mountain-line Step 7: Prepare power transmission on mountain-line Step 8: Transmission on mountain-line

\section{CONCLUSION}

Before the implementation of this project, several discussions and assessment concluded that it would need at least 60 days to restore power supply that not only people would not be able to tolerate the pain caused by long-time power outage but also the corporate could not afford to the loss. So it is necessary to restore power supply in the shortest time. After understanding the situations after the typhoon, this study used TOC to produce five focusing steps and find out possible bottlenecks the construction of project may face before considering how to make a breakthrough and pull all the non-bottleneck support to do it.

During emergent reparation operations, a full investigation on the location of available resources and possible difficulties was conducted. Through buffer management mechanism, it brought all resources and uncertain factors under effective control to fully support the reparation work and ensure it will be carried out smoothly. Thus under the full support of resources and in-time application of the management strategy of critical chain scheduling, the single circuit successfully transmitted in 18.5 days and the full transmission through two circuits was completed in 21 days. It once again proved the excellent results by applying TOC to project management.

\section{REFERENCES}

Goldratt, E.M., 1997. Critical Chain. 1st Edn., North River Press, Great Barrington, MA, USA., ISBN10: 0884271536, pp: 246.

Goldratt, E.M., 1999. Theory of Constraints. 1st Edn., North River Press, Great Barrington, MA, USA., ISBN-10: 0884271668, pp: 160.

Guiterrez, G.J., P. Kouvelis, 1991. Parkinson's law and its implications for project management. Manage. Sci., 37: 990-1001.

Kerzner, H., 2009. Project Management: A Systems Approach to Planning, Scheduling and Controlling. 10th Edn., Wiley, New York, ISBN-10: 0470278706, pp: 1120.

Lee, R.G. and S.H. Zhang, 2005. TOC-from limited to unlimited. China Productivity Center, Taipei.

Schragenheim, E. and B. Ronen, 1991. Baffer management: Adiagnostic tool for production control. Produ. Inventory Manage. J. Sec. Quarter, 74-79. 